\title{
ТРАНСКРАНИАЛЬНАЯ ФИЗИОТЕРАПИЯ В КОМПЛЕКСЕ С МЕТОДАМИ АФФЕРЕНТНОГО ВОЗДЕЙСТВИЯ В ЛЕЧЕНИИ И РЕАБИЛИТАЦИИ БОЛЬНЫХ С ЦЕРЕБРАЛЬНЫМ ИНСУЛЬТОМ
}

\author{
А.В.Мусаев, Ф.К.Балакишиева, С.Г.Гусейнова, *С.С.Имамвердиева, Л.Р.Нуриева \\ Азербайджанский НИИ Медицинской Реабилитации, Баку
}

$\overline{\mathbf{P}}$ ост числа сосудистых заболеваний мозга ставит перед медициной и обществом в качестве первоочередной задачи реабилитацию больных, перенесших инсульт. Острота проблемы определяется тем, что церебральный инсульт (ЦИ) занимает второе место в структуре смертности от болезней системы кровообращения (после ишемической болезни сердца) и первое место среди причин инвалидизации населения. Инвалидизация больных обусловлена, прежде всего, нарушением двигательных функций, потерей трудоспособности, а также психологической и социальной дезадаптацией. В связи с этим совершенствование старых и разработка новых методов реабилитации, как в ранние, так и поздние постинсультные периоды является важным направлением современной нейрореабилитации. Основным инвалидизирующим фактором после перенесенного ЦИ являются двигательные расстройства. Двигательная система при этом страдает целиком, затрагивая как надсегментарные, так и сегментарные отделы.

Фундаментальные исследования последних лет с использованием экспериментальных моделей на животных, а также неинвазивных методов картирования мозга у человека представили неоспоримые доказательства способности коры головного мозга к значительной функциональной перестройке. Как саногенетические, так и патологические преобразования в ткани мозга обеспечиваются механизмами нейропластичности; они лежат в в основе как истинного восстановления, так и компенсации нарушенных функций при повреждениях мозга. Эти данные послужили толчком к развитию новых технологий в области двигательной реабилитации; появилось множество новых методик и технологий физиотерапии, массажа, лечебной гимнастики.

Одним из перспективных путей оптимизации реабилитационного про-цесса, усиления механизмов нейропластичности мозга является комплексное применение трансцеребральной физиотерапии и методов афферентного воздействия - новейших видов кинезотерапии. Доказано, что трансцеребральное применение ЛФФ сопровождается генерализованным характером ответных реакций, включением ведущих нейрогуморальных и иммунных механихмов гомеостаза. Особенно высокой чувствительностью к трансцеребральной терапии обладают срединно расположенные структуры ЦНС - гипоталамо - гипофизарная и лимбическая системы мозга. Направленное воздействие физических факторов на область очага поражения в головном мозге вызывает дестабилизацию устойчивого патологического состояния и перестройку деятельности мозга на новое устойчивое состояние, близкое к норме. Основными видами трансцеребральной физиотерапии являются: 1) трансцеребральная импульсная электротерапия; 2) трансцеребральное воздействие электрическим полем высокой и ультравысокой частоты; 3) трансцеребральное воздействие электромагнитными волнами сверхвысокой частоты; 4) трансцеребральная магнитотерапия; 5) трансцеребральная лазеротерапия (рис.1).

В комплексной восстановительной терапии, постинсультных больных ведущее место принадлежит кинезотерапии. Современная кинезотерапия предусматривает применение различных методик, направленных на мобилизацию компенсаторных возможностей, усиление афферентной импульсации, улучшение постуральной устойчивости; при этом всё шире внедряются новые подходы ориентированные на восстановление определенной двигательной функции. Одним из таких новых подходов является метод форсированной тренировки паретичных конечностей, предложенный в 1993 г. Е.Таub и соавт. (рис.2).

*e-mail: dsevinj@mail.ru 

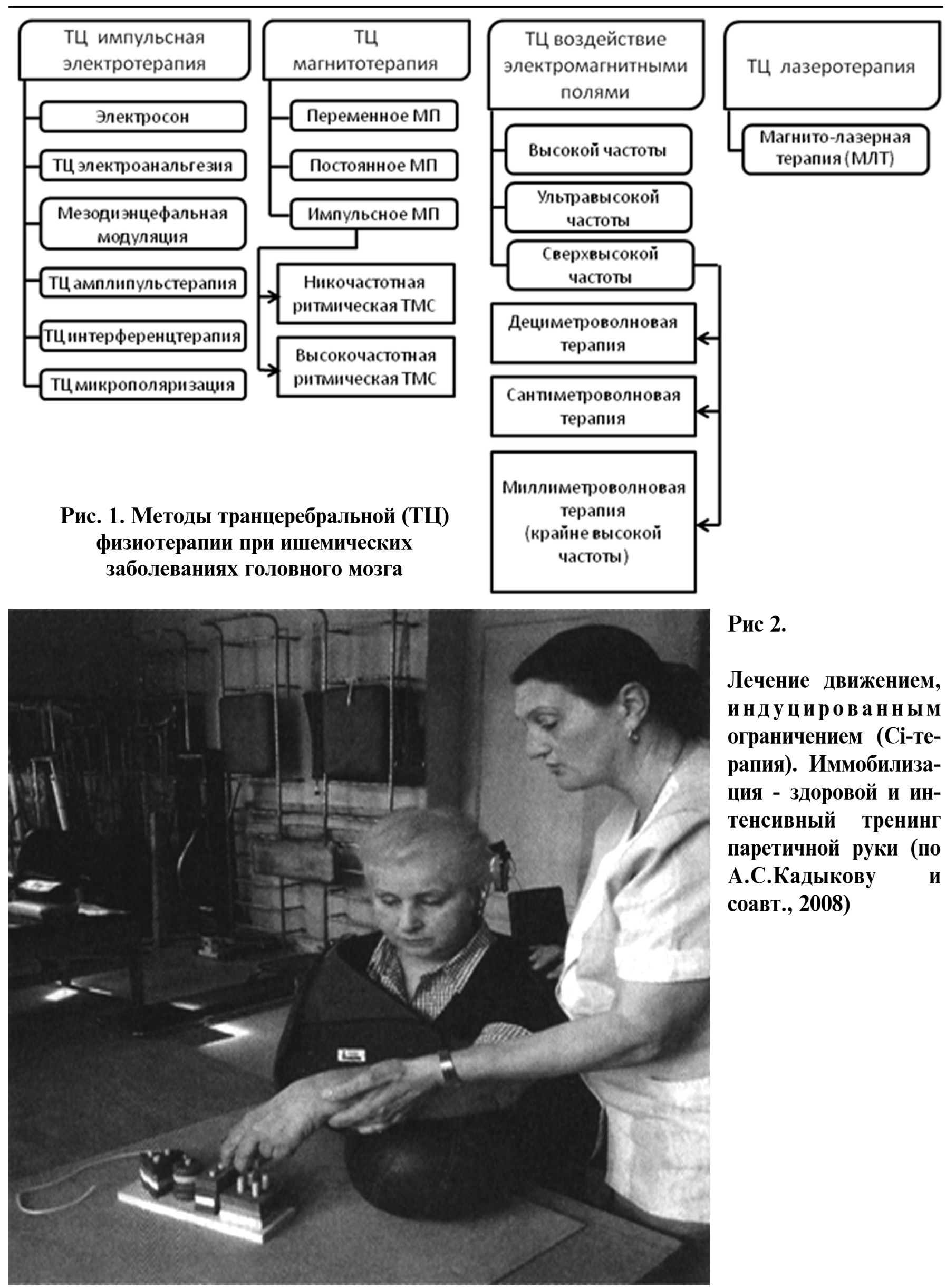

Рис 2.

Лечение движением, и н д у и р о в а н ны м ограничением (Сі-терапия). Иммобилизация - здоровой и интенсивный тренинг паретичной руки (по А.С.Кадыкову и соавт., 2008) 
Метод назван авторами "лечение движением, индуцированным ограничением" - "constraint induced movement therapy" (Сi-терапия). Принципы Сі-терапии обоснованы экспериментальными исследованиями на приматах. Сущность предложенного метода заключается в том, что здоровая рука фиксируется с помощью специальных приспособлений к туловищу на 5-6 часов в день в течение двух недель; тем самым создаются условия, при которых всё внимание пациента фиксируется на использовании паретичной руки. В некоторых работах показано, что фиксирование здоровой руки у больных с инсультом как в ранние сроки (3-9 месяцев), так и с давностью гемипареза от 2 до 5 лет, приводит к улучшению функции тренируемой конечности. В них

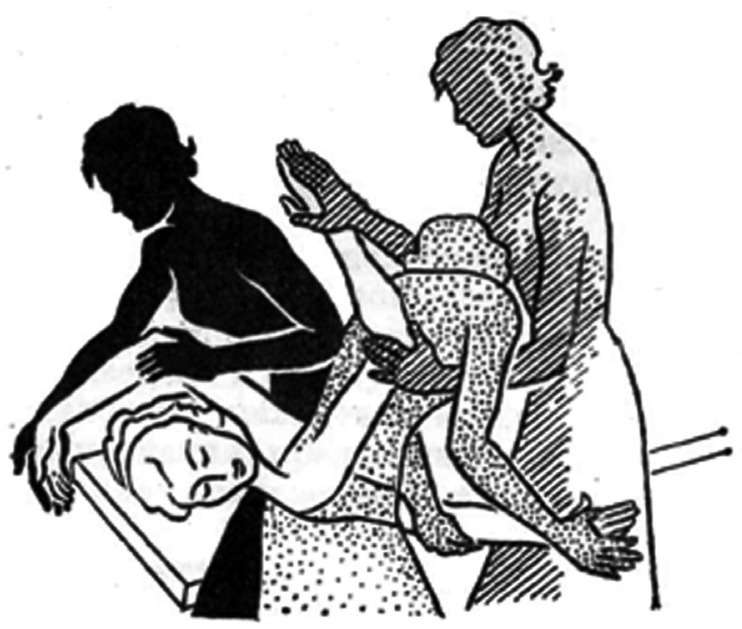

Рис. 3. Проприоцептивная нервно-мышечная фасилитация (упражнение для руки)

В последние годы большое внимание уделяется комбинированному или сочетанному применению транскраниальной магнитной стимуляции (ТМС) и различных методов кинезотерапии. R.Lindenberg с соавторами (2010), применяя у пациентов после инсульта двухполушарную ТМС в сочетании с кинезотерапией, отмечали улучшение двигательной функции на фоне значительной активации интактных двигательных зон в полушарии, ипсилатеральном очагу поражения. S.Ackerley с соавторами (2010) у пациентов с субкортикальным инсультом использовали стимуляцию моторных зон Тета-волнами (Theta Bust Stimulation) в сочетании со стандартизованными тренировками по обучению точности захвата, что подтверждено также влияние Сі-терапии на перфузию в моторных зонах, принимающих участие в планировании и выполнении движения.

К перспективным методам кинезотерапии относится также методика проприоцептивной нервно-мышечной фасилитации (ПНФ), разработанная Г.Кабатом из Чехословакии. Сущность методики заключается в улучшении работы мышц путем специфической стимуляции проприорецепторов нервной системы. При помощи рук подаются импульсы определённому количеству проприорецепторов одновременно или в течение какогото времени: это оптимизирует взаимодействие нервов и мышц, улучшает работу парализованных конечностей (рис. 3 и 4).

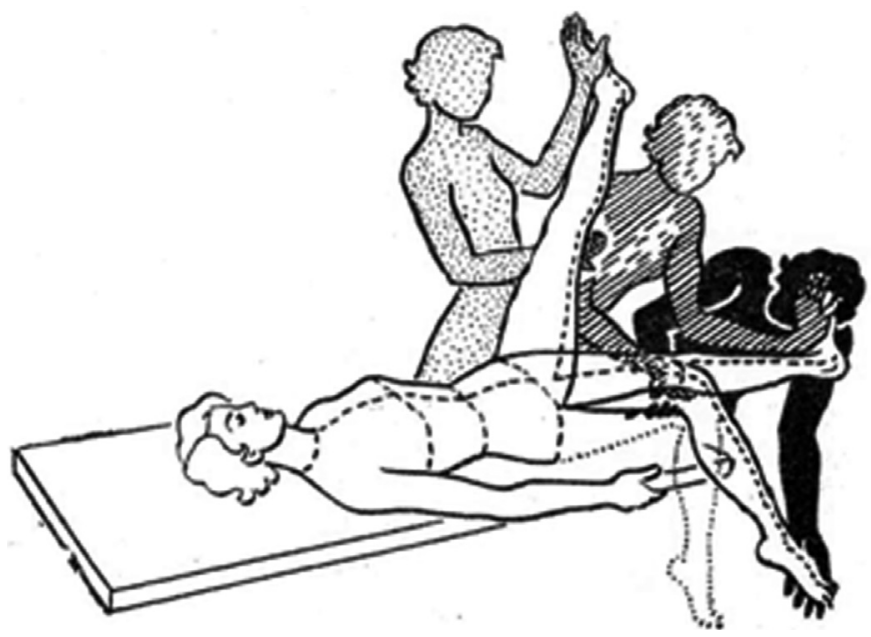

Рис. 4. Проприоцептивная нервно-мышечная фасилитация (упражнение для ноги)

улучшало кинетику паретичной руки.

В нашей клинике выполнено исследование, в котором для реабилитации больных с церебральным инсультом использовалась двухполушарная ТМС в комплексе с методами кинезотерапии (Сi-терапия и ПНФ). В наших предыдущих исследованиях, также посвященных применению различных методик магнитной стимуляции при постинсультных двигательных нарушениях, показано, что ТМС обладая как локальными так и отдалёнными эффектами, активирует корковые мотонейроны, облегчает передачу нервного импульса по кортикоспинальному пути, а также способствует реорганизации функциональных систем мозга, усилению процессов нейропластичности (рис.5). 


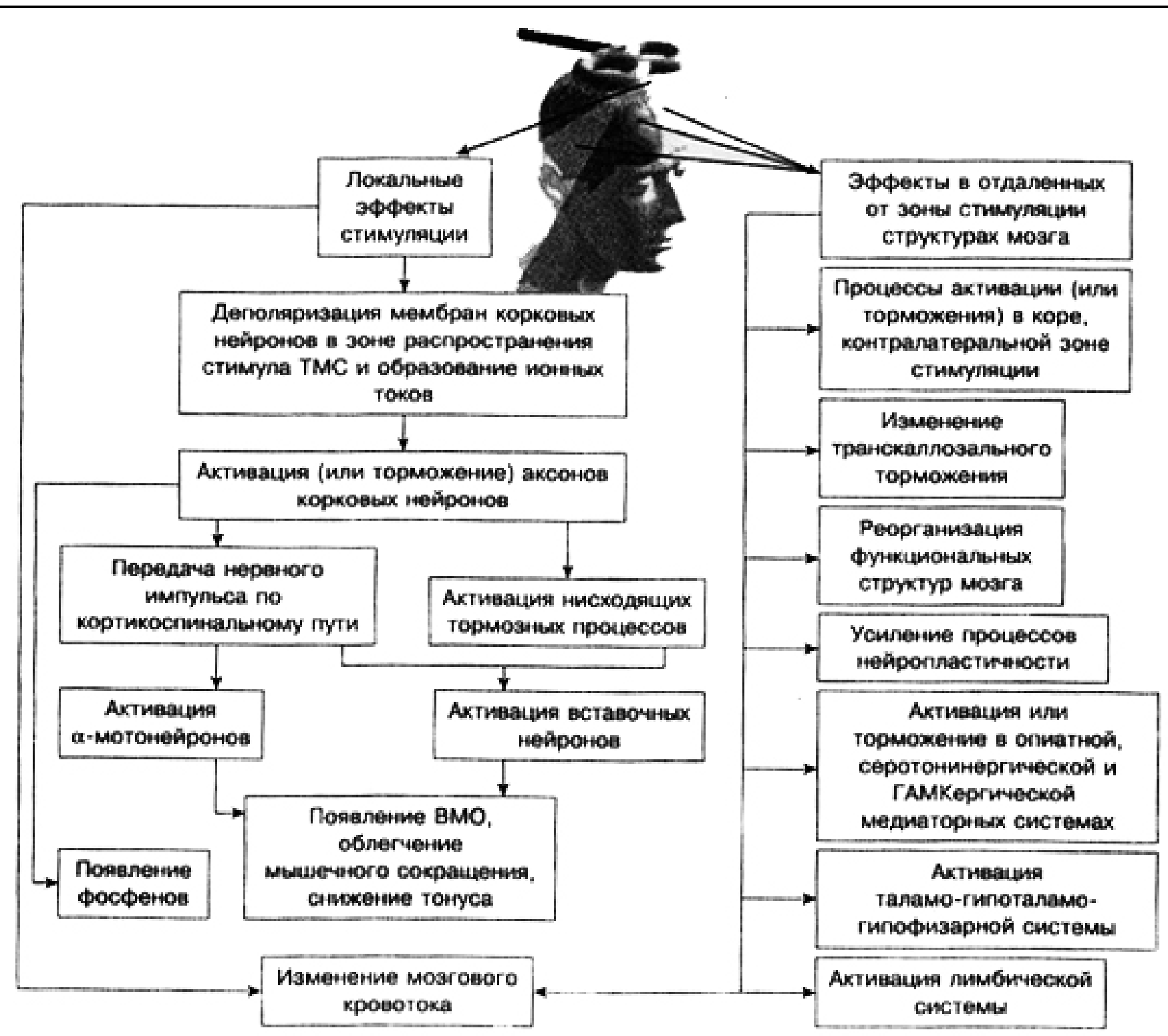

Рис 5. Эффекты ТМС непосредственно в зоне распространения и в отдаленных от зоны воздействия структурах головного мозга

В настоящем исследовании была применена 2-полушарная ТМС с воздействием на корковые моторные центры как поражённого, так и интактного полушария мозга. Выбор методики кинезотерапии у постинсультных больных зависел от тяжести и характера распределения парезов конечностей.

Под наблюдением находилось 57 пациентов с

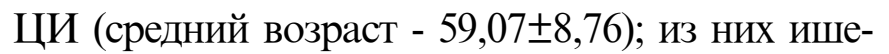
мический инсульт перенесли - 52, геморрагический - 5 больных. Методы исследования включали: 1) клиническое неврологическое исследование; 2) изучение бытовой активности больных с помощью шкалы Бартел; 3) оценку состояния центрального нейромоторного аппарата мето- дом ТМС; 4) изучение когнитивных функций с помощью шкал Mini Mental State Examination (MMSE) и Frontal Assessment Battery (FAB); исследования проводились до и после лечения. Все больные принимали транскраниальную магнитную стимуляцию от аппарата "Magstim Rapid" с помощью сдвоенного койла на корковые моторные центры как поражённого, так и интактного полушария мозга; в лечебный комплекс включали специальные методики кинезотерапии - "лечение движением, индуцированным ограничением" (Сі-терапия) и проприоцептивную нервномышечную фасилитацию (ПНФ).

Клинические наблюдения показали, что проводимое комплексное лечение оказывало 
благоприятное влияние на моторные функции у больных с церебральным инсультом. Так, увеличение объёма активных движений отмечалось у 39,4\% больных, снижение спастичности - у 32,2\%, улучшение походки и вертикальной позы - у 39,3\%, появление новых движений - у 33,5\%. Согласно общепринятым критериям эффективности, клиническая эф- фективность составила 54,5\%.

Под влиянием проводимой терапии у постинсультных больных улуч-шалась повседневная бытовая активность, что подтверждалось положительной динамикой показателей по всем пунктам шкалы Бартел. Суммарная оценка возросла от $54,0 \pm 3,7$ до $78,5 \pm 3,3$ баллов $(\mathrm{p}<0,01)$ (таб. 1$)$.

Динамика показателей шкалы Бартел у больных с ЦИ (М \pm м), н=40

\begin{tabular}{|l|l|l|}
\hline Пункты шкалы & До лечения & После лечения \\
\hline Приём пищи (10) & $5,3 \pm 0,6$ & $7,0 \pm 0,5^{*}$ \\
\hline Персональный туалет (15) & $2,5 \pm 0,4$ & $3,6 \pm 0,4^{* *}$ \\
\hline Приём ванны (15) & $4,0 \pm 0,6$ & $6,6 \pm 0,1^{* *}$ \\
\hline Одевание (15) & $1,4 \pm 0,4$ & $1,8 \pm 0,4$ \\
\hline Контроль тазовых функций (20) & $18,8 \pm 0,6$ & $19,3 \pm 0,6$ \\
\hline Туалет (10) & $5,8 \pm 0,6$ & $7,4 \pm 0,5^{*}$ \\
\hline Вставание (15) & $9,9 \pm 0,8$ & $12,3 \pm 0,6^{*}$ \\
\hline Передвижение (20) & $10,6 \pm 0,6$ & $12,9 \pm 0,5^{* *}$ \\
\hline Подъём по лестнице (15) & $6,0 \pm 0,5$ & $8,3 \pm 0,4^{* *}$ \\
\hline Общий балл: & $54,0 \pm 3,7$ & $78,5 \pm 3,3^{* *}$ \\
\hline
\end{tabular}

Примечание: в скобках указано максим.количество баллов по пункту;"-p $<0,05 ;$ ***- p $<0,01$

Нейропсихологическое тестирование по балл увеличился с $21,1 \pm 5,6$ до 24,7 44,7 специальным шкалам выявило уменьшение $(\mathrm{p}<0,05)$. Анализ отдельных составляющих по выраженности когнитивных нарушений. шкале FAB показал, что на фоне лечения у Анализ отдельных пунктов шкалы MMSE по- больных улучшалось выполнение простой и казал, что у пациентов несколько улучшились сложной реакции выбора, проб на динамичетакие показатели, как память, ориентация, ский праксис. Общий балл увеличился с способность к устному счету (таб. 2); общий $14,2 \pm 1,5$ до $15,7 \pm 2,1(\mathrm{p}<0,05)$.

Таблица 2.

Результаты нейропсихологического тестирования больных с ЦИ $(\mathrm{M} \pm \mathrm{M}, \mathrm{H}=40)$

\begin{tabular}{|l|l|l|l|}
\hline & Пункты шкалы & До лечения & После лечения \\
\hline \multirow{4}{*}{$\sum$} & Ориентация (5) & $6,4 \pm 2,1$ & $7,8 \pm 3,7^{*}$ \\
\cline { 2 - 4 } & Память (5) & $1,5 \pm 0,8$ & $3,2 \pm 1,1^{*}$ \\
\cline { 2 - 4 } & Устный счёт (5) & $3,1 \pm 1,0$ & $3,4 \pm 1,2$ \\
\cline { 2 - 4 } & Общий балл & $21,1 \pm 5,6$ & $24,7 \pm 4,7^{*}$ \\
\hline \multirow{4}{*}{} & Динамический праксис (3) & $2,3 \pm 0,6$ & $2,5 \pm 1,0$ \\
\cline { 2 - 4 } & Концептуализация (3) & $2,1 \pm 0,5$ & $3,0 \pm 0,1^{*}$ \\
\cline { 2 - 4 } & Реакция выбора (3) & $2,4 \pm 0,7$ & $3,3 \pm 0,2$ \\
\cline { 2 - 4 } & Общий балл & $14,2 \pm 1,5$ & $15,7 \pm 2,1^{*}$ \\
\hline
\end{tabular}

Примечание: в скобках указан максим.балл по пункту; *-р<0,05;

Повторное исследование нейрофизиологических показателей методом ТМС констатировало улучшение параметров вызванного моторного ответа (порога вызывания, латент- ности, амплитуды) как в поражённом, так и интактном полушарии мозга $(\mathrm{p}<0,01)$; оно сопровождалось также сокращением времени центрального моторного проведения (рис.6). 


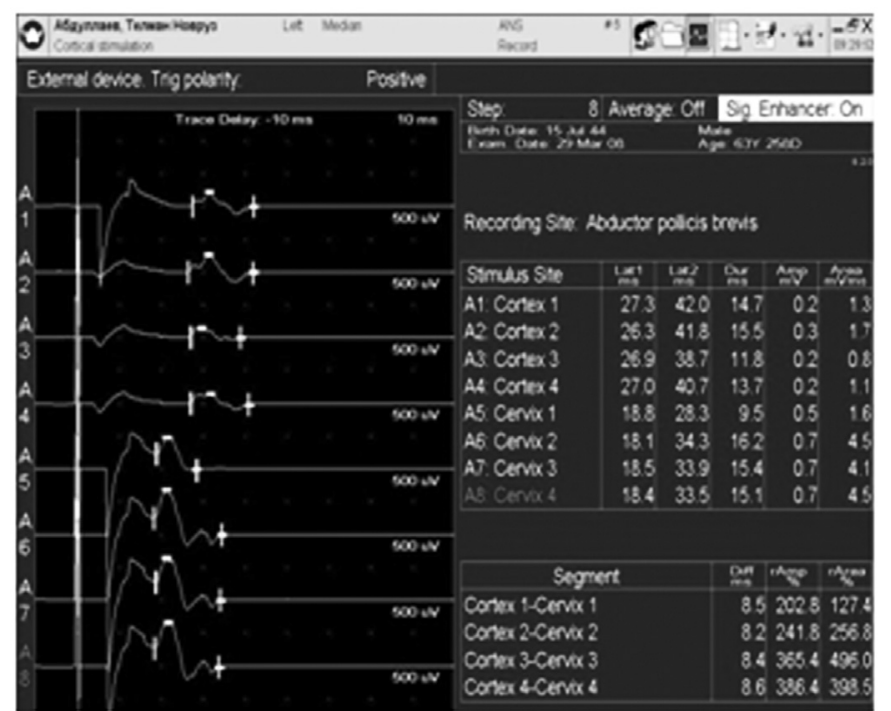

Показатели ВМО до лечения

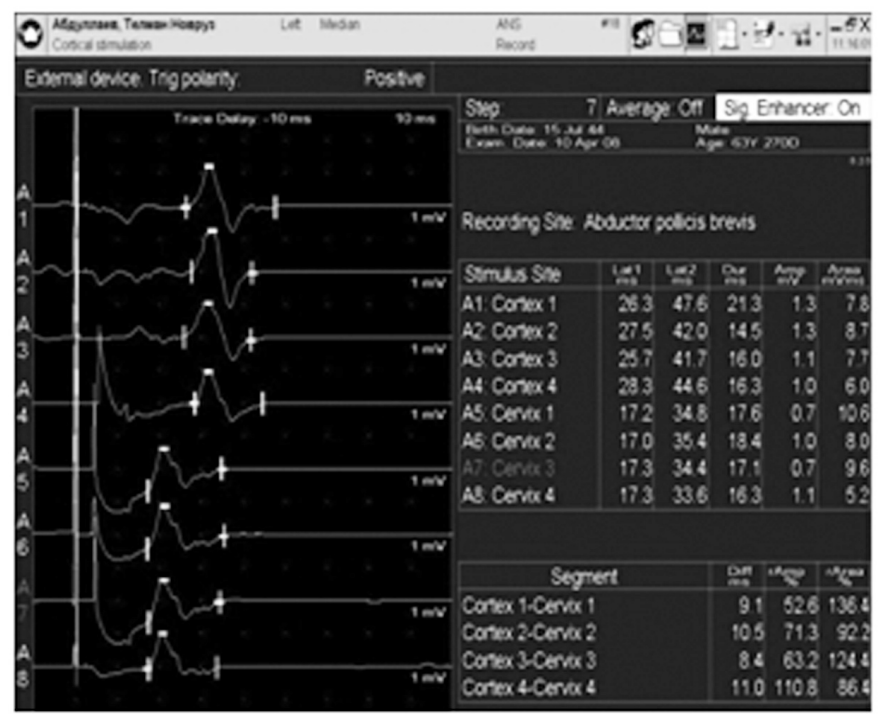

Показатели ВМО после лечения

Рис 6. Показатели ВМО у больного с ишемическим инсультом до и после курса лечения ритмической ТМС

Таким образом, наши наблюдения показали, что использование двухпо-лушарной ТМС как в восстановительном, так и резидуальном периодах инсульта приводит к улучшению двигательных функций, повышению бытовой активности больных, улучшению функционального состояния центрального нейромоторного аппарата и когнитивной сферы. Включение в лечебный комплекс специальных методик кинезотерапии - Сi-терапии и ПНФ способствует ускорению реабилитационного процесса, что связано с усилением потока афферентной импульсации с периферии, процессами функциональной церебральной реорганизации и нейропластичности. При выборе методики кинезотерапии следует учитывать следующий принцип: применение методики форсированной тренировки паретичных конечностей (Сi-терапии) целесообразно у инсультных больных с преобладанием пареза в верхней конечности, а ПНФ - при равномерном распределении пареза в руке и ноге.

\title{
XÜLASə
}

\section{SEREBRAL INSULTLU XəSTӘLӘRINN MÜALIĊ VӘ REABLITASIYYASINDA TRANSKANIAL FIZIOTERAPIYANIN AFFERENT TOSIRLI ÜSULLARLA KOMPLEKSDӘ TӘTBIQQI}

\author{
A.V.Musayev, F.K.Balakişiyeva, S.Q.Huseynova, S.S.İmamverdiyevaa, L.R.Nuriyeva \\ Elmi-Tadqiqat Tibbi Borpa İnstitutu, Bakl, Azərbaycan
}

Serebral insultlu xəstələrdə transkanial maqnit stimuliyasiyasından (TMS) və kinezoterapiya metodlarından ibarət müalicə kompleksinin effektliliyi öyrənilmişdir. Ötən tədbiqatlarımızdan fərqli olaraq TMS təsiri beynin həm zədələnmiş həmdə intakt yarımkürəni əhatə etmişdir. İşin yeniliyini həmdə müasir kinozeterapiya metodlarının - "məhdudlaşdırmadan irəli gələn hərəkətlə müalicə” (Bi-Terapiya) və proprioseptiv sinir əzələ fassilitasiyası (PYF) tətbiqi təşkil etmişdir. Müalicənin nəticələri kliniki, neyrofizioloji və biokimyəvi tədqiqatların məlumatlarına əsasən qiymətləndirilirdi. Apar1lan kompleks terapiyanın təsiri altında serebral insultlu xəstələrdə hərəki funksiyaların yaxşılaşması, məişət aktivliyinin artması, kortikospinal traktın funksional vəziyyətinin yaxşılaşması və biokimyəvi dəyişiklərin tənzimlənməsi müşahidə olunurdu. Alınmış nəticələr tətbiq edilmiş kompleks müalicə metodikasının serebral insultlu xəstələrin reablitasiyasında perspektivliyini təstiqləyir. 


\title{
SUMMARY
}

\section{APPLICATION OF TRANSCRANIAL PHISIOTHERAPY IN A COMPLEX WITH METHODS OF AFFERENT INFLUENCE IN REHABILITATION OF PATIENTS WITH A CEREBRAL STROKE}

\author{
A.V.Musayev, F.K.Balakishiyeva, S.G.Huseynova, S.S.Imamverdiyevaa, L.R.Nuriyeva \\ Research Institute of Medical Rehabilitation, Baku, Azerbaijan
}

Effectiveness of the medical complex including transcranial magnetic stimulation (TMS) and methods of a kinesitherapy at patients with a cerebral stroke (CS) is studied. Unlike the our pre-vious researches TMS was carried out both on affected, and on an intact hemisphere of a brain. For the first time in work the modern methods of a kinesiteraphy "constraint induced movement therapy" (Ci-therary), and a proprioceptive neuromuscle facilitation (PNF) are applied. Results of treatment were estimated according to clinical, neurophysiological, neuropsychological and biochemical investigations. The subjective improvement of health in patients under the influence of complex therapy accompanied by reduction of movement deficiency, increase of daily activity, functional state of corticospinal tract and correction of biochemical shifts. It confirms availability of this complex method in treatment and rehabilitation of poststroke patients. 